\title{
The Growing Relation between Environment and Public Health
}

\author{
Françeska Korançe 1,2* \\ ${ }^{l}$ Polis University, Rr. Bylis, Autostrada Tiranë-Durrës, Km.5, Kashar 1051, Tiranë, Albania. \\ ${ }^{2}$ Build Green Group, Rr. "Ibrahim Kodra”, Nd. 8, H. 7, Ap. 10, Tiranë 1001, Albania.
}

Received 19 January 2021; Revised 08 March 2021; Accepted 25 March 2021; Published 01 June 2021

\begin{abstract}
Introduction: Environmental health is deteriorating worldwide. Evidence shows that exposure to air, water and soil pollution has caused many deaths worldwide, a trend that is increasing day by day. Health consequences from exposure to environmental pollutants range from cancer, lung disease, heart disease and a series health problems which often lead to death. The majority of pollution related deaths happens mostly in low and middle-income countries. Environmental and pollution health related issues are not getting the attention they deserve in Albania. The main purpose of this article is to identify the relationship between environmental problems and public health consequences, by analysing public policies, case studies and instruments for measuring environmental health indicators. The article also presents suggestions regarding development of Environmental Medicine in Albania, and Public Health Tracking methods. Methods: Qualitative method is thoughtfully used in this article. Specifically, literature review methodology is used to identify environmental indicators that directly affect public health, adequate policies and instruments for the protection of public health, as well as environmental health at the international and national level. Qualitative method is used to reveal and evaluate the topic through multiple facets covering relevant contextual conditions. This method helps identifying the link between public and environment health indicators in a real-life situation, and to understand the relationship between these indicators in the Albanian context. Results and Discussion: Albania lacks a specific measurement system of Environmental Public Health Tracking, as well an established methodology for linking environmental and public health. Potential capacities for measuring environmental and health indicators are limited at the national level, thus, the public health policies do not clearly and fully integrate environmental health indicators for the protection of public health. Vocational training in health and environment is being practiced through various disciplines, but there is a need for specialized environmental medicine health professionals, with adequate competences in the field. Conclusions: The correlation between environment and public health is gaining attention nationally and globally. As in other countries, the need for Environmental Medicine professionals is growing also in Albania. Strong correlations between of environmental pollution indicators (air, water, land pollution) and public health indicators (such as infant and general mortality, morbidity rates, respiratory diseases, etc.) have increased in the last years. Use of instruments (such as EPHT), a fully integrated university curricula and a specific discipline of Environmental Medicine should be made a priority not only nationally, but also globally as environmental problems such as climate change do not recognize national borders. In order to manage the rising cases, states need to be resilient, and build appropriate research based policies and action plans to prevent the occurrence of environmental related public health consequences.
\end{abstract}

Keywords: Environmental Medicine; Public Health; Environment Health; Policy; Indicators; Albania.

\section{Introduction}

Monitoring of environmental indicators is used globally, as a tool of reliability to better understand environmental condition and change dynamics. Interest in this perspective was initially initiated by the Seventh Group at the 1989

* Corresponding author: franceska.korance@gmail.com

$>$ This is an open access article under the CC-BY license (https://creativecommons.org/licenses/by/4.0/).

(C) Authors retain all copyrights. 
Paris Summit, where the leaders of the world's major industrial powers recommended that the Organization for Economic Co-operation and Development (OECD) [1] develop environmental indicators in support of integrated environmental management, a time from which many agencies have made efforts to establish a comprehensive system of environmental indicators at the national level. But, monitoring of environmental indicators has been the focus of indepth research, especially during the last 10 years, as an integral part of increasing scientific capacity, such as medical and environmental laboratories.

Lately, monitoring of environmental indicators has also been a tool to identify potentially human health risks, as well as a legal tool of environmental quality control under national and international agreements and protocols. Monitoring reports have shown that exposure to air, water and soil pollution caused nine million premature deaths globally [1]. Health consequences and death causes differ around the world; they range from cancer, lung disease, heart disease and the likes of them. These premature deaths are related to, or are the result of direct contact with the polluted environment. Environmental pollution is the cause of more than nine million deaths worldwide, which brings it at $16 \%$ of the total worldwide deaths, causing three times more deaths in humans than HIV, tuberculosis and malaria combined [1]. Environmental pollution is now responsible for 15 times more deaths than wars and all other forms of violence combined. From air pollution alone, around 4.2 million of deaths occur each year; while in 2020 this figure reached its peak at 6.67 million deaths [1]. Moreover, according to an EU report, one in eight deaths is related to pollution [2]. No country is unaffected by the consequences of environmental pollution. However, $92 \%$ of deaths occurred in low and middle income countries [3]. The most vulnerable communities are hit the hardest by environmental pollution consequences [4]. For example, Eastern and South Eastern Europe experiences higher exposure to particulate matter polluters compared to West Europe [5]. Pollution in developing countries like Albania is getting worse, and above all, it is still not getting the attention it deserves. It is therefore essential to study this issue rigorously.

Despite the efforts up until now, most of the time the conceptual framework for the development of environmental indicators has failed to integrate public health indicators [5]. Many environmental quality indicators such as toxic emissions or pollutants discharge level permits for different type of activities are based solely on environmental regulatory compliance requirements, often without reference to potential environmental impacts on human health, even though it is widely known that environmental factors contribute greatly and to a high number of harmful impacts on human health. The mass production of new synthetic chemicals and the widespread use of fossil fuels have significantly expanded the spectrum of health risks to humans from exposure to toxic environment pollutants. Dramatic progress in industrialization, urbanization and technology has also increased public perception and awareness of the health risks associated with environmental indicators. Environmental and public health are not separate areas, and any attempt to calculate the dynamics of each without considering the other is unreliable.

Currently, one of the priority areas in this regards, is the clear identification of mechanisms for linking the development of environmental indicators with public health trends and the definition of integrated methods for assessing the potential impact of environmental exposures on public health. These health-related environmental indicators can be used as a formal tool to represent the link between environmental exposures and adverse health outcomes. The correlation between public health problems and environmental indicators often seems logical in principle. But scientific research is often lacking in this regards. These connections ought to be studied and analyzed in more detail, in order to allow the necessary interventions to improve environmental indicators, public policies and consequently improve human health.

There is still little knowledge of the specific mechanisms by which most environmental agents induce disease in humans. Furthermore, it is noted that the available information regarding the potential environmental impacts on human health comes mainly from epidemiological investigations and animal studies [5]. This data cannot be used to conclusively determine the environmental cause of disease in human health. Despite the uncertainty over the causal link between environmental factors and diseases in humans, on the other hand, there is considerable scientific evidence that exposure to environmental hazards can significantly increase the risk for a range of adverse effects on human health [5]. The increasing rate of numerous health problems, including various types of cancer, reproductive disorders, neurological and respiratory impairments, as well as overall mortality, has been highly associated with exposures to environmental pollutants [5]. Most of the problems in this regard, are rooted in the methodological approach used to identify the correlation between these two variables. New forms of methodological and theoretical studies need to be used and further developed, so that the information collected in the form of health statistics is made available, to further correlate the impact of environmental indicators of health. The use of reliable health-based environmental indicators, as standardized representatives about the impact that the environment exerts on human health can also be considered as the most effective methodology to date. These tools can also be a very useful approach to better understand the complex relationship between these two variables [6]. As a practical matter, the choice of a 'healthbased' environmental indicator often depends on available data that no longer reflect the current scientific understanding of the environmental etymology of diseases. It should be noted that although much effort has been made recently to develop indicators to support environmental policy and regulatory compliance [6], agencies need to pay attention to adjusting their monitoring and oversight programs to better respond to the need for health-based 
environmental management measures. Health-based environmental indicators can be useful tools for both the decisionmaking process and the protection of public health. They should be measurable, specific and sensitive, available when socially demanded, cost-efficient, prevalent, based on public concerns and have potential to increase prevention of environmental pollution related diseases and health related consequences [6].

Research in this field remains minimal, especially in the Albanian case, due to insufficient scientific knowledge about the causal or correlated link between exposure to certain environmental indicators and the adverse health effects associated with them. In this context, the main purpose of this study is to identify the relationship between environmental and human public health associated problems, by analyzing in depth policies and instruments for measuring both environmental and health indicators, using case studies and by offering various suggestions for the development of Environmental Medicine professionals in Albania, which is now missing. To achieve its overall purpose, this article is structured in four main sections, introduction, methods, results and conclusion. In the introductory section are presented the main concepts, context and aim of the research. In the methods section the research methodology is shortly described. Meantime, the body of literature findings introduces us on the environmental pollutant levels seen as hazardous to public health in general, achievements to date of agencies for the control of diseases and toxic substances in the framework for the environmental public health surveillance system, as well as the importance of adequate policies for the protection of both public health and environmental health in the era of digitalization will be emphasized, focusing mainly on EPHT as an instrument for tracking environmental public health. The article extends the analysis as well with an in-depth analysis of the main policies and institutions responsible of public and environmental health in Albania, together with two case studies, which clearly describe the strong correlation between environmental and public health in Albania. Furthermore, the article, in the discussion section highlights the importance and development of specific undergraduate or postgraduate programs in the field of environmental medicine in the Albanian, with few basic competences that a student in the field of Environmental Medicine should acquire in order to be resilient. The final part of this study shortly presents the main conclusions and recommendations of the article.

\section{Materials and Methods}

One of the biggest limitations still faced by this field of study is the lack of accurate methodologies to measure with high efficiency, or to correlate on a large scale, environmental pollution with public health consequences. Literature shows that the most traditional approach is mainly based on the pressure-response model. In this regard, qualitative methodology is thoroughly used in this article, with the aim to reveal and evaluate the topic through multiple facets, covering relevant contextual conditions. Qualitative methodology in this specific case helps identifying the link between health and environmental indicators in a real-life situation, and understanding the relationship between them in the Albanian context. The study is based mainly on literature review, with the clear aim to identify environmental indicators that directly affect the public health effects. The use of national and international literature is an important part of the methodology, as this topic not developed specifically and according to the indicators in Albanian context. In addition, this methodology helps to identify adequate policies and instruments for the protection of public and environmental health at the international and national level, referring to the Albanian context in particular. Below is a flowchart explaining the main methodology concept used in this article.

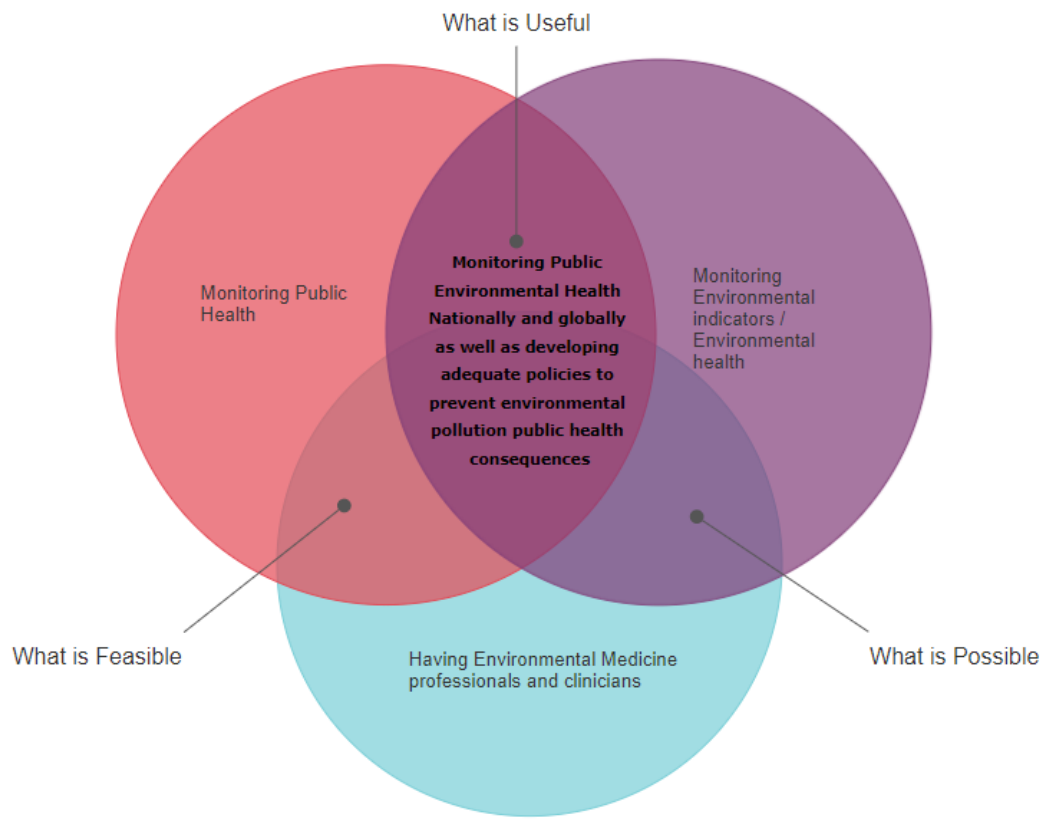

Figure 1. Research methodology concept flowchart 


\section{Results}

\subsection{Environment Polluting Agents and their Potential Impact on Public Health}

This part of literature analysis will focus on providing existing frameworks related to environmental medicine, i.e. the identification of environment polluting agents and their potential impact on public health. Health-based environmental indicators can be represented through different types of metrics, which are mainly illustrated by the method: "Environmental exposure - adverse health outcome" [6]. There is no current consensus on the exact criteria for selecting health-based environmental indicators. Most of the basic principles used to select environmental indicators include: the degree of measurement of the indicator, the reliability of the indicator, the validity and also the availability of data for the indicator of interest. However, typical environmental indicators such as levels of environmental pollutants, toxic emissions and industrial emissions, which are built on these principles, do not tell much about the potential negative effects on human health. Therefore, public health criteria should also be used, such as assessing the potential of the indicator to prevent harmful environmental impacts on human health and its ability to address public concerns about such impacts [6]. Different countries have adopted international and national environmental standards regarding levels of concentration for environmental indicators within appropriate limits for the protection of public health. In this context, we will analyze here two major subgroups, air and water pollutants (we will not consider soil pollutants here, as soil pollutants go through a longer and more complicated process, while these two groups often have immediate effects).

The first group, air pollutants, refers not only to some of the (external) air pollutants, which are carcinogenic, but also to indoor ones. Many human carcinogens are abundant both in ambient air and indoors. Aerosol compounds have a greater toxicity than gaseous compounds due to their small size (solid or liquid) in the atmosphere; they have a greater penetration capacity. Gaseous compounds are more easily eliminated from our respiratory system. These particles are capable of damaging the lungs and can even enter the bloodstream, leading to the premature death of millions of people each year. Furthermore, aerosol acidity $([\mathrm{H}+])$ appears to significantly increase the production of secondary organic aerosols (SOA), but this aspect is not supported by all scientific teams. Studies have shown, for example, that indoor benzene concentration may exceed those outdoors [6]. The vehicles generate gasoline, 1, 3butadiene and polycyclic aromatic hydrocarbons. No guarantee of safety can be provided at any level of exposure to these carcinogens. All estimates of increased risk of carcinogenic air pollutants are based on mathematical extrapolation from animal studies or on the increased risk of exposure to high concentrations. The WHO has published 'unit risk factors' that allow a more detailed risk assessment (expressed as increased risk of acquiring a type of cancer as a result of lifelong exposure to a unit concentration of carcinogenic). For example, lifetime exposure to benzene of $17 \mu \mathrm{g} / \mathrm{m}^{3}$ is estimated to be associated with an increased risk of 1 in 10,000 . Unit risk at $1 \mu \mathrm{g} / \mathrm{m}^{3}$ is estimated to be $6 \times 1066$. [6] At the other hand, indoor air pollution should is much too often overlooked. All pollutants, except ozone (which reacts quickly with furniture and appliances and disappears), are part of indoor environment. Internal concentrations are partly driven by external sources and by specific internal sources. Carbon monoxide and nitrogen dioxide are produced by fire and cooking. Recent studies have led to evidence of a link between nitrogen dioxide and respiratory infections, deteriorating lung function in women with asthma, increased sensitization, and response to allergens [6]. Long-term exposure to low levels of carbon monoxide is thought by some to have lasting neurological effects. Exposure to tobacco, burning biomass for cooking and space heating is a major problem. Chronic obstructive pulmonary disease is associated with such exposures and other effects have been reported, including cataract induction. Regulating indoor pollutant concentrations is difficult, only few countries have produced indoor air quality standards together with the outdoor standards, which poses great risks to countries that haven't [6].

Secondly, water pollution is also a major group for consideration. The quality of drinking water is assumed that is safe to drink. Yet this is neither certain nor uncertain. Accidental contamination of water supplies occurs occasionally in all countries: as such is mentioned the accidental contamination of water with aluminum sulphate contaminated in Camelford (Cornwall), UK in 1988 [7]. The quality of water supplies is improving in many countries, but the rate of improvement is uneven. The WBO reported in 2010 that 874 million people still did not have access to improved (i.e. satisfactory) sources of drinking water [7]. In some countries, for example, in the UK, concerns have been expressed about the potential effects of so-called disruptive endocrine chemicals on human health [8].

Table 1. Summary of main pollutants and their sources [9]

Arsenic for example, is found in high concentrations in many countries like Argentina, Canada, Chile, China, Japan, Mexico, Philippines, and the United States. Recent findings of arsenic concentrations over 70 times the national standard of $0.05 \mathrm{mg} / \mathrm{L}$ have been found in countries like the West Bengal, addressing the urgent need to study it. Water poisoning with arsenic has led to evidence of chronic toxicity, including melanosis, hyperkeratosis, and skin cancer.

Nitrates, for example drained from agricultural land) can enter drinking water. Consumption of baby food prepared with such water can lead to poisoning due to methemoglobin produced by the interaction between nitrite ions and hemoglobin The reaction is an oxidative, but the exact mechanism is unclear. Cyanosis can occur in very young children. In fact, $0.5-$ $10 \%$ of the population in 15 European countries may be exposed to nitrate levels above the WHO standard of $50 \mathrm{mg} / \mathrm{L}$ each year. 


\begin{tabular}{|c|c|}
\hline Lead & $\begin{array}{l}\text { Main sources of Lead comes from pipes and welding joints, especially in areas that are supplied with acidic water (soft } \\
\text { water areas). Lead accumulates gradually in the human body and can damage the central nervous system. A number of } \\
\text { studies have linked lead uptake to a reduced IQ. Mercury and cadmium are examples of other metals that contaminate water } \\
\text { supplies in the same way. }\end{array}$ \\
\hline Fluoride & $\begin{array}{l}\text { Fluoride is added to water in some places to provide protection against tooth decay. An effective protection is provided at } \\
\text { levels of } 0.5-1.0 \mathrm{mg} / \mathrm{L} \text {. The difference between protective and toxic effects is unfortunately very narrow, and the effects } \\
\text { vary from dental fluorosis to skeletal fluorosis, which have occurred in some areas. High levels of fluoride are found in } \\
\text { countries in the Middle East, Africa, and North and South America. }\end{array}$ \\
\hline $\begin{array}{l}\text { Biomass } \\
\text { vapours }\end{array}$ & $\begin{array}{l}\text { Biomass, including wood, crop residues and animal feces. It is mainly used for cooking and heating in developing } \\
\text { countries. Combustion of these materials causes severe exposure, mainly indoor, to polycyclic aromatic hydrocarbons } \\
\text { (PAHs) and other airborne carcinogens. It is estimated that tens of thousands of deaths from lung cancer can be prevented } \\
\text { each year in developing countries, for example, through increased ventilation. }\end{array}$ \\
\hline Aflatoxins & $\begin{array}{l}\text { Aflatoxins are a class of toxic metabolites produced by certain species of fungi, including Aspergillus flavus, which can } \\
\text { contaminate ground nuts, hardwood nuts, and whole grains. Laboratory studies have demonstrated the carcinogenicity of } \\
\text { aflatoxins in rodents, primates and fish. Hepatocellular carcinoma (HCC) has been observed in numerous species and the } \\
\text { liver is the primary target organ. HCC is one of the most common cancers worldwide with a large geographical variation in } \\
\text { incidence. The number of people exposed to high levels of aflatoxin worldwide is unknown, but it is likely to be at least } 0.5 \\
\text { billion. If we assume a relative } 5 \% \text { risk, then it follows that the number of preventable deaths from liver cancer would be at } \\
\text { least } 80 \% \text { of the total } 85,000 \text { deaths that occur each year in exposed populations in developing countries, i.e. } 68,000 \\
(85,000 \text { is estimated as half of all liver cancer deaths occurring in developing countries). Prevention can be effective with } \\
\text { simple tools, such as storing wheat in dry conditions. }\end{array}$ \\
\hline $\begin{array}{l}\text { Landfill } \\
\text { pollutants }\end{array}$ & $\begin{array}{l}\text { Landfills in developed and developing countries are a source of exposure to carcinogens such as dioxins, polychlorinated } \\
\text { biphenyls, arsenic, cadmium, nickel, PAHs and some solvents (including benzene). Illegal landfills in developing countries } \\
\text { are probably more common, which increases the risk. They also are more often contaminated with toxic chemicals, and } \\
\text { closer to homes than in developed countries. The Food and Agriculture Organization of the United Nations (FAO) has } \\
\text { estimated that } 120,000 \text { of the 500,000 tones of toxic waste produced worldwide are currently stored in Africa. }\end{array}$ \\
\hline $\begin{array}{l}\text { Air } \\
\text { pollutants }\end{array}$ & $\begin{array}{l}\text { Air pollution can cause many diseases, allergies and even death in humans; it can also cause damage to other living } \\
\text { organisms such as animals and food crops and can damage the natural or built environment. Air pollutants cause a number } \\
\text { of respiratory, heart, lung diseases, cancer etc. depending on their type, the degree of individuals' exposure, his/her health } \\
\text { status and genetic. }\end{array}$ \\
\hline
\end{tabular}

\subsection{Achievements to Date of Agencies for the Control of Diseases and Toxic Substances in the Framework of Environmental Public Health Surveillance System}

Various agencies including the Centre for Disease Control (CDC) and the Agency for Toxic Substances and Disease Registry (ATSDR) have worked to develop the framework for the environmental public health oversight system [10]. Despite the potential benefits, setting up such a system is still a complex task. One of the main challenges is the lack of understanding of who is responsible for data collection, and who will have the authority to access the data collected by others. Another limitation stems from insufficient cooperation between agencies. Environmental and health agencies that are the main collectors of information about health-related outcomes, but do not have a clear mechanism for communicating it to the public. Even when agencies report data on analogue results, lack of coordination often leads to miscommunication. Improved collaboration between environmental and health agencies will significantly increase the potential of a data collection system regarding environmental-related health effects. [10].

Recent and ongoing developments regarding monitoring and testing methods will definitely provide more opportunities for the use of various indicators, such as biomarkers of exposure. Biomarkers are several types of indicators that represent the most important approaches to the development of health-based metrics for environmental quality. Biomarkers can be used at various points of extension of the 'exposure-health effect' as exposure markers (blood lead levels, plasma cholinesterase depression levels) and effect markers (DNA adaptations, chromosome breakdown, chromosomal aberrations, etc.). [10] Over the past 30 years, the field of biomarkers has expanded greatly thanks to the early and specific monitoring of cellular responses to various disease states, and also exposures to environmental elements and chemical agents. Biomarkers enjoy some success as predictors of health outcomes for a number of clinical diseases, but their application in chemical exposure risk assessments is still limited. Biomarkers can be classified into different categories such as level of exposure, effect and sensitivity etc. Currently, "omic" biomarkers (i.e., genomic, proteomic, and metabolic) are the main classes of biomarkers. These markers represent a continuum of cellular responses to exposures to various contaminants or chemical elements and provide links to the mechanisms of cell damage, cell death or even carcinogenic cell transformation [10]. One of the key potentials of biomarkers is their ability to record and measure toxic agents in the human body. Instead of concentrations of environmental pollutants in environmental indicators, biomarkers can provide current levels of environmental toxins, which are available in the human body. Given the fact that these levels reflect a cumulative dose resulting from inhalation through all routes of entry (inhalation, ingestion, and dermal contact), biomarkers can serve as very comprehensive estimates of individual exposure. Two other advantages of biomarkers result from their advanced time position in the continuity of the exposure effect. Representing an internal dose, they are positioned closer to the potential health effect making them the best tools for assessing human health risks. Moreover, biomarkers serve as 
early signalers of impacts in future human health, which gives them significant predictive value and allows for effective preventive action. [10] The application of biomarkers on the other hand poses great challenges and can be limited by several factors, including considerations regarding measurability, specificity, sensitivity, cost effectiveness and invasiveness of sampling techniques. Despite recent efforts in the development and validation of biomarkers, there are not many specific toxic biomarkers that can be used on a broader basis. In addition, the interpersonal variability of markers within the population, the high cost involved, and their invasive nature, are factors that currently limit them from widespread use as a health-based environmental indicator. Undoubtedly, biomarkers will represent one of the first choices in the near future. Health-based environmental indicators embody an integrated approach which provides an opportunity to combine knowledge of health risk assessment, toxicology and public health with environmental monitoring and more importantly in the future, computer models.

Another example of measuring environmental indicators that affect human health, is the Chronic Human Health Indicator developed by the US EPA Office of Pollution Prevention and Toxicity. The main idea is to create a metric for assessing environmental health risk related to human health based on risk information, exposure, patterns and size of the exposed population. The current indicator reflects the replacement doses taken by integrating Toxic Release Inventory (TRI) emissions with standard exposure assumptions and case modelling, weighted by the toxicity of the chemicals and the number of people exposed to them. Despite the current shortcomings in its exposure component (associated with the TRI model), this method creates a valid health-based indicator that can be used as a control tool for environmental management. The risk-based approach can be implemented using region-specific information and current pollutant monitoring data as input parameters. Combined with standard U.S. EPA exposure models and local census data, this method can produce a much better assessment of environmental health risks across population segments than just measurements of toxic concentrations of environment, and is overall cost efficient. Although the current indicator considers only air exposure, of particular importance is the ability of this model to provide indicator analysis, given the fact that most environmental pollutants exert their negative impacts on human health through multiple exposure routes. However, this methodology does not address the severity of adverse health outcomes, nor does it provide quantitative risk assessments. The model is designed more to bring indicators for relative comparisons, related to the risk of environmental impacts on human health and should be used only for its primarily purpose [10].

\subsection{The Importance of Adequate Policies for the Protection of Public and Environmental Health in the Era of Digitalization}

The world is facing tremendous challenges regarding globalization and climate change. It is important to identify early signals of negative impacts and early analysis of environmental indicators, especially from a public health perspective. Observing changes in environmental indicators can help to understand the consequences on the public health. The Principle of Precaution, which is enshrined in European Directives and the national laws of the Member States, is based on two general criteria: (a) appropriate public action must be taken in response to limited but credible evidence of potential and substantial damage; (b) the burden of proof has shifted from demonstrating the presence of risk to demonstrating the absence of risk [11]. Reasons for the adoption of this Principle (e.g. impossibility of setting thresholds for carcinogenic exposures; long latency periods for many modern diseases; uncertainties regarding mechanisms of action; large-scale effects of new pollutants) and considerations of its limitations (e.g. what is the minimum level of suspicion leading to precautionary action) make the Precautionary Principle paralyzing, as risks tend to be assessed independently of benefits). One of the reasons to take early warnings seriously is the limited understanding of many serious diseases possibly influenced by environmental factors such as Alzheimer's and Parkinson's diseases, amyotrophic lateral sclerosis, and many types of cancer [11]. A fusion between science and the Precautionary Principle should help protect people more effectively from environmental hazards. The link between science and policies is in fact, one of the most difficult challenges we have to face today. The role of international agencies is likely to need strengthening in the coming years.

\subsubsection{EPHT Instrument - Monitoring Public Environmental Health}

One answer to this problem from both a scientific and a policy point of view is the Environmental Public Health Tracking (EPHT) system. EPHT can be defined as: "Continuous collection, integration, analysis and interpretation of data related to environmental hazards, exposure to environmental hazards, human health effects potentially related to exposure to environmental hazards. It involves disseminating the information learned from this data and implementing strategies and actions to improve and protect public health." [12]. EPHT is also a useful tool for strengthening the framework of driving forces, pressures, condition, exposures, health effects and immediate actions. EPHT promotes a systematic integration of the above components, taking into account both environmental and health indicators, in the context of the real leadership, and the pressure and the existing state of these indicators and their change over time. EPHT aims to promote a resilient society by analyzing complex data sets, addressing diverse audiences and supporting environmental health messages tailored to each audience [12]: 
- Public: Information to support individual changes in collective attitudes and actions.

- Professionals and stakeholders: Tailored information for health professionals, planners, environmental managers and researchers.

- Decision makers: Integrated health and environmental information for fully informed decision-making and create opportunities to reduce the multiplier impacts associated with rapid urbanization, globalization and climate/social/economic (sustainable) development [12].

Such general and generic categories also include resource managers, planners, economists, conservatives, indigenous and locally influenced communities, community developers, and many other essential actors. They are all important, given the dynamics, which focuses on the key issue: how to improve the health of the population. The EPHT approach seeks to achieve its goal of "healthy, informed communities" by empowering environmental and public health practitioners, health care providers, community members, policymakers and others to make informeddriven decisions that influence in health while maintaining appropriate data protection measures [12]. In conclusion, EPHT is an instrument/program that can support cross-sectoral integration of information, to better assist decisionmaking in health outcomes at the national and global levels, through the means of a comprehensive approach and ecological improvement of public health. This method should be adapted worldwide, including Albania.

\subsubsection{The Environmental Public Health Instrument (According to the Wisconsin Department of Health Sciences [13])}

Another identified tracking instrument/program contains open access relevant data for all citizens on a range of environmental public health topics. Any person can access online and choose from different categories, for example air quality and airborne toxins $\left(\mathrm{PM}_{2.5}\right.$ levels, ozone, etc.) and sub-theme of average annual cancer risk per people or per year, in which he wants data and more information on these specific pollutants (for example their source of pollution in the environment). After selecting the desired options, the person can access the above data for each city and state. The portal also provides answers to the most frequently asked questions about air quality, such as who the main air pollutants are, where the air pollution comes from, the sources of exposure, health effects, knowledge on the risk assessments, data source, policy and government measures taken for reduction air pollution etc. On the other hand, this open access platform specifies that these data do not provide specific and scientific links between a person's health and the environment because the science that links air pollution to health and disease is complex [13]. Many factors like time and other exposures can have a significant impact in this regard. The platform provides a good opportunity for awareness at the civic level, as well as the opportunity, same as EPHT instrument, to make better policies to protect environmental and public health in this regard.

\subsection{Policies and Institutions Responsible for the Protection of Public and Environmental Health in Albania}

The term "public health" according to the Albanian legislation and Law no. 10 138, dated 11.5.2009 "On Public Health", is the overall organized efforts of society to prolong life, to prevent disease and promote good health of the entire population. The term "environmental health" is found only as a module. In one of courses of study in the Medical and Technical Sciences Faculty in Tirana, Albania, this module provides students with knowledge about air pollution, the effects of atmospheric pollution on the body and preventive measures, drinking water hygiene, food hygiene, indoor hygiene (mostly indoor work environment) [14]. Recently, changing of the legal framework regarding the new global trends, in terms of protecting public health from pollution has been very slow. The last change made in this regards was Law no. 10, 440, dated 07.07.2011, "On Environmental Impact Assessment" which states that public and private projects, among others, will be assessed for the impact they have on the population and human health. [14] At the national level, data reporting related to the environmental indicators monitoring in Albania, such as water, air, noise, biodiversity, forests, industrial pollution, is performed by the National Environment Agency, together with the Institute of Public Health. National Environmental Agency laboratory is responsible for conducting tests related to the basic parameters of natural water analysis, including nitrates, nitrites, phosphates, total phosphates, $\mathrm{pH}, \mathrm{NKO}, \mathrm{NBO} \%$, conductivity, suspended solids and ammonia etc [15]. The annual report of the National Environmental Agency (NEA) contains information designed mainly for citizens and government institutions.

The information in NEA reports is somehow but not fully connected to human health impacts. For example, in the report, quality of coastal waters is determined to determine the level of microbial load of water on these beaches (assessment for the presence of microorganisms E. Coli and S. Fecal), which directly affects the health of the population for example:

- Lagoon water quality (assessment of indicators such as water temperature, transparency, $\mathrm{pH}$, alkalinity, salinity, electrical conductivity, dissolved oxygen, $\mathrm{NKO}, \mathrm{NBO}_{5}$, nitrites, nitrates, ammonia, ortho-phosphates, suspended matter and chloride), where mussels, fish, etc. are cultivated; 
- Assessment of surface water, through indicators such as temperature, $\mathrm{pH}$, alkalinity, salinity, electrical conductivity, dissolved oxygen, $\mathrm{NKO}, \mathrm{NBO}$, nitrites, nitrates, ammonia, $\mathrm{P}_{\text {total }}, \mathrm{PO}_{4}$, suspended matter, etc., which serve for soil irrigation agricultural, are fish habitats etc. thus affecting food safety; groundwater monitoring ( $\mathrm{pH}$, hardness, ammonia, trace elements, etc.) [15].

- The NEA report, also monitors air quality according to elements PM10, PM2.5, NO2, SO2, O3, CO and BTEX, which explains the health effect of this particular matter, like worsen heart disease, heart attack, arrhythmia, lung disease, central nervous system damage, reproductive system, cancer, premature death; Nitrogen Oxides $\left(\mathrm{No}_{\mathrm{x}}\right)$ which damage the liver, lungs, spleen; Sulphur Dioxide $\left(\mathrm{SO}_{2}\right)$ which worsens asthma, reduces lung function, causes respiratory tract irritation, headaches, restlessness and anxiety; Ozone $\left(\mathrm{O}_{3}\right)$ which is related to respiratory health problems, decreased lung function, worsening asthma, premature death; and also carbon monoxide $(\mathrm{CO})$, which is strongly related to heart problems, nervous system damage, headaches, dizziness and fatigue [15].

- Furthermore, measurable standards for outdoor air quality apply mainly to dust and gases. Data on indoor air are lacking and work environment air is limited.

In terms of noise assessment, NEA mainly monitors urban noise in the main cities of Albania. Their high level causes nervousness, anxiety and depression in particular citizens. The NEA also measures Biodiversity indicators, where the behavior of plants and animals testify to the level of pollution in these areas and their impact on the balance of the natural ecosystem. Furthermore, NEA also measures soil-related indicators ( $\mathrm{pH}, \mathrm{N}, \mathrm{P}, \mathrm{K}, \mathrm{Cu}, \mathrm{Fe}, \mathrm{Ca}, \mathrm{Mg}$ and heavy metals, such as $\mathrm{Cd}, \mathrm{Cr}, \mathrm{Co}, \mathrm{Ni}, \mathrm{Pb}$ and $\mathrm{Zn}$ ) [15], based on the fact that environmental pollution and especially of Heavy Metals, is one of the most pressing environmental issues locally and globally that is directly related to the negative effects on the world and human health. Negative effects of heavy metal poisoning have also been identified [15]. Examples in this regard are Cadmium (Cd) which damages the lungs (bronchitis), liver (toxaemia), kidneys, bones; Chromium $(\mathrm{Cr})$ which has found to be related to lung cancer; Nickel $(\mathrm{Ni})$ linked to decreased lung function, cancer; Lead $(\mathrm{Pb})$ with direct health effects like nausea, vomiting, abdominal pain, anorexia, constipation, insomnia, anemia, irritability, nervousness, boredom, loss of coordination, hyperactivity, confusion, memory loss, irritability, coma and even death; and finally Zink (Zn), which has been strongly linked to anemia, pancreatic damage, decreased levels of high-density lipoprotein and blood cholesterol.

Even though the National Environmental Agency is the institution responsible for reporting environmental indicators related to water, air, noise, biodiversity, forests, industrial pollution and land in cooperation with other national institutions, however, environmental and biological monitoring is insufficient at the national level [15]. Even though the reporting clearly stated the environmental indicators change and environmental health, it does not make a clear link with the public health. Both citizens and government institutions cannot make a correlation of their own, and furthermore prevent the damages to the public health.

In this regards, is important to mention another institution in the context of environmental health, the Institute of Public Health (IPH) also located in Tirana, Albania, which is responsible for the development and application of prevention and control of diseases, injuries, disabilities, environmental health detrimental factors, and the development and application of general good health promotion, in close cooperation with other national and international institutions [16]. The purpose of this institution is to monitor the public health condition, to identify in time and to solve scientifically identified public health problems; identifying and monitoring health risk determinants; undertaking and increasing the level of information; educate the public and increase awareness of health related problems; stimulating, coordinating and supporting the initiatives of institutions and communities in terms of activities undertaken by them to identify and solve these health problems; stimulating and supporting draft laws and regulations aimed at protecting public health; make ongoing training and education of public health workers and professionals; evaluating the effectiveness, accessibility and quality of both population-based and patient-based health services; enrich the scientific research to provide better and innovative solutions to health problems as well as to establish effective strategies on disease control and prevention [16].

One of the departments of IPH is the Department of Assessment and Training of Public Health Risks (or otherwise the Department of Health and Environment), which exercises its activity in close cooperation with other scientific departments of IPH, the University Hospital Centre "Mother Teresa", public health directorates/services by region/ district, public sectors outside the field of health and various non-public organizations/organizations inside and outside the country. The Department of Health and Environment is organized in six main sectors:

\section{Water and Sanitation Sector}

This sector conducts studies and research related to environmental risk assessment and its public health impact. It provides technical-professional assistance to specialists in public health, hygiene, service and the State Health Inspectorate, provides training and qualification of environmental health specialists through seminars, as well as 
training and university education in Public Health. Follows and keeps under constant control, through the analysis of data from health structures, the situation and quality of drinking water supply at national level, and finally gives recommendations and tasks for implementation by assessing risk factors. This structure also prepares the annual report on the quality of drinking water at the national level, based on the annual reports of the regional structures of Public Health. Organizes studies and takes measures for the implementation of the National Environmental Monitoring Program, especially for monitoring of drinking water and surface water. Compiles analytical indicators for each laboratory, cooperates and consults with microbiologists and chemists, for various problems related to analytical results. Its facilities include laboratories for microbiological, physico-chemical, toxicological analysis (heavy metals, oils \& greases, PAHs and pesticides) and are attached to the Department of Health and Environment. Water analyzed in these laboratories represent the water source, water intake, storage or water supply network in which the water sample was taken (for general public or for private entities) [16].

\section{Sector of Environmental Epidemiology and Air Quality Control}

This sector aim is to analyze and further investigate the impact of environmental factors on the health of the population; monitoring and evaluation of environmental factors as well as the development of epidemiological studies in the field of environment and health; assess and manage environmental risk in public health and develop continuing education activities in the field of Environmental Epidemiology; ensure continuous monitoring of urban air quality in some cities; monitor indoor air (mainly in public places such as schools and public institutions); provide expertise on air quality monitoring and risk assessment of air pollution; coordinate work based on indicators recommended by $\mathrm{WHO}$, as well provide the data standardization and to compare them with data from various countries in the region or European countries; conduct field epidemiological studies and finally, its aim it's also to provide training for professionals working in the field of Environmental Epidemiology and air quality control [16].

\section{Sanitary Physics Sector}

The Sector of Sanitary Physics is the unit responsible for the measurement, monitoring and evaluation of physical pollutants, such as noise, vibration, artificial and natural lighting and electromagnetism. This sector assesses the impact on health mainly through assessment of exposures from physical pollutants in urban and residential areas (noise, electromagnetic waves, etc.). This sector is also responsible for hearing and visual assessment, in different vulnerable age groups. Monitoring of national noise level by this sector is made in order to identify the most problematic areas, and more importantly to apply remedial measures on the harmful effects on public health in the affected areas. In cooperation with the ministry, this sector develops national policies on physical pollutants, standards, guidelines and materials to promote a healthy society. In cooperation with central institutions also, and in the framework of gathering different complaints from various individuals or businesses, this sector carries out noise level measurements and maintains a regular documentation. It also has the mission of drafting information and educational packages, related to physical pollutants and harmful effects on human health, in order to raise awareness of the population by age groups on physical pollutants and educate the population regarding harmful effects as well as effective measures for disease prevention [16].

\section{Occupational Health and Toxicology Sector}

This sector aims to conduct studies on the impact of harmful toxicants on employees' health, to recommend measures related to safety and health at work, and evidently increase their quality and productivity at work. By participating in the preparation of laws and bylaws related to occupational safety and health, this sector influences by perfecting the work processes for the elimination of occupational factors and pests by taking measures to increase the ability to work and work efficiency. This sector is responsible for creating satisfactory and clean, hygienic-sanitary environments in the inside of different work environments, as well as raising the health education of employees at the national level. This sector carries out research and study topics using the hygienic-sanitary methods of observation, in life context, were they survey the working conditions in different enterprises. The monitoring keeps tract of chemical and toxicological method that determines the levels of occupational pests and chemical pests such as gases, vapours and toxic substances. They also monitor basic working conditions, mainly using statistical method for health status study and occupational morbidity [16].

\section{Nutrition and Food Safety Sector}

This sector has the clear mission to develop knowledge, tools and strategies aiming to prevent and control of diseases and their food origin. This overall structure is responsible for monitoring the nutritional status of the population and the impact of diet and eating habits on health, especially, in the detection and resolution of conditions due to nutritional deficiencies important for public health. This sector is responsible also for raising awareness and promote healthy nutrition. In cooperation with local institutions, this sector conducts anthropometric measurements, clinical examinations, biochemical analyzes and food consumption tests to assess the nutritional status and dietary habits of the population [16]. 


\section{Laboratories Sector}

This sector includes a whole infrastructure of laboratories, including the laboratory of food microbiology and mycology; water, air and soil microbiology laboratory; water and sanitation chemistry laboratory; laboratory of food chemistry and determination of iodine in urine; laboratory of analytical instrumental chemistry and safety and finally laboratory of quality control.

All of the above sectors, part of Department of Health and Environment, play an important role in preventing and controlling the public health through the quality control of drinking water, air, food. Sanitary physics, i.e. issues research study related to both public and environment health. The ultimate goal of all the activity of this department is the sustainable improvement and protection of public health regarding environmental toxicity. In this context, IPH publishes national public health reports in Albania, which generally include measuring and analysing mortality indicators, such as life expectancy, daily mortality rate, mortality rate by specific causes (e.g. ischemic heart disease, neoplasms, diabetes, chronic obstructive pulmonary disease, cerebrovascular disease, digestive diseases, injuries, mental and behavioral disorders, infectious diseases), infant and maternal mortality, morbidity burden (proportional and cause-specific). It also includes other risk factors such as smoking, alcohol consumption, physical interactivity, high body mass index, hypertension, high blood glucose, high cholesterol, diet, etc. [17]. The studies are mainly community-based and not individual-patient based, so they are more of a cross-sectional surveillance, as in the case of studies in the epidemiology (and immunology) of infectious diseases [16].

In addition to the Institute of Public Health, which is the most important institution in the context of environmental health of the population, another supporting institution is the State Inspectorate of Labour and Social Services, which provides services to employees, businesses and care centers in accordance with the implementation of DCM for occupational health. According to the inspectorate, all entities that exercise their activity in the territory of the Republic of Albania, regardless of the type of activity and the number of employees must provide a doctor in the workplace. Medical analyzes and tests, related to the professional medical examination at work, are mandatory in health institutions, public or private, licensed according to the legislation in force for licensing in the Republic of Albania [18].

The National Institute of Statistics in Albania (INSTAT) is another supporting institution in the field of environmental health that issues an annual report on public health indicators in cooperation with health institutions. Data include the number of primary health care, mainly regarding number of visits to health centres, ambulances and polyclinics; women counselling; child counselling and vaccine coverage. Regarding the secondary hospital service, data mainly represent the number of patients in public and private hospital institutions, and the number of the day they stay. In addition, this institution collects data regarding the mental health service, which include the number of doctors, psychologists, etc., as well as number of hospital beds where these diseases are treated [19].

The above analysis shows us that Albania lacks a specific system of Environmental Public Health Tracking that include all in one data on indicators related to the topics of public and environmental health. There are shortcomings in the methodology for grouping and measuring more indicators, such as those related to climate change for instance. Report from IHP department are usually outdated, and not consistent. Most of the time data gathered are not open to the public. The data usually are separately, related to the most common diseases in the Albanian population, without specifying their possible causes in relation to the environment. In addition, in the health system structures in Albania, the operation and potential capacities for measuring environmental and health indicators are limited at the national level. Albania also lacks a special study department or university program that educated generations of professionals specialized in the field of environmental medicine dealing at the patient-doctor level. Vocational training in health and environment is widely distributed in public health disciplines, at the Medical University in Tirana, but only regarding certain subjects or courses of Environmental Engineering, at the Polytechnic University, Faculty of Civil Engineering, Agri-Environment at the Agricultural University, etc., including both private institutions of higher education. The University of Medicine in Tirana for example, has two main departments: the Department of Family Physician and Occupational Diseases and the Department of Public Health. Doctors investigating and treating occupational diseases are general ones. A special department in this regards, has not been developed yet in this faculty, and in Albania, although many diseases are caused by pollution of the internal or external work environment. Thus, in addition to environmental medicine, occupational medicine is still not fully been consolidated as a specialized branch of study in Albania, while the practices of some developed countries have included it in a department or student program such as Environmental Medicine and Occupational Medicine. However, even in developed countries many environmental medicine physicists are largely involved in public health practices and use primarily quantitative data management skills that focus more on populations than on the clinical paradigm that focuses on individuals [20]. 


\subsection{Case Studies}

\subsubsection{Exposure of Oil Workers to Chemical Pollution in Ballsh, Albania}

The petrochemical industry of Ballshi town in Albania has negatively affected the environment due to the toxicity of aromatic polycyclic hydrocarbons (PAHs) and aliphatic ones, which can easily bio-accumulate in the tissues of the human body. The study conducted by the research Çipa [21], consisted in on-source measuring the environmental indicators of pollution near the oil refinery area in Ballsh, as well as measuring the health indicators of pollution from biological samples of workers working there, furthermore, her study also included citizens living near this industry [21]. In addition to environmental PAH measurements and biological samples, other data were obtained from medical tests like blood cholesterol levels by specific subunits like triglycerides, phospholipids, aspartate aminotransferasesAST, alanine aminotransferases-ALT, total bilirubin, creatine and urea. In addition, Biochemical markers for lipid profile, liver and kidney function were analyzed by the turbidimetric method [21].

The results of the study showed, among other things, that the oil refinery in Ballsh could be considered as one of the main factors in the contamination of lands and waters with PAHs in its vicinity. Compared to the limit values of the PAHs set by national and international legislation, many areas near the oil industry were contaminated, while the waters had high values of carcinogenic PAHs. As a result, land and water stations were assessed as dangerous to public health due to their direct contact with these samples.

Refinery workers in Ballsh and also citizens nearby, were exposed for a relatively long time to PAH and resulted in high levels. This conclusion was the result of comparing the maximum permissible levels in human serum for PAH determined by the Occupational Safety and Health Administration with those obtained from the study sample. With the increase of years of employment, the level of carcinogenic aromatic polycyclic hydrocarbons also increased in the workers of the petrochemical industry. Moreover, the study population tended to develop cardiovascular disease or arteriosclerosis disease due to exposure to aromatic and aliphatic polycyclic hydrocarbons. This tendency was not observed for hepatotoxic diseases or renal dysfunction [21].

The study simultaneously assessed the concentration of aromatic polycyclic hydrocarbons in environmental matrices and in the serums of workers professionally exposed in the oil refinery in Ballsh. It is a valuable example that can be followed by environmental and medical professionals. The study suggested extending measurements of aromatic polycyclic hydrocarbons or other pollutant indicators to the health of workers in the workplace, in order to determine occupational exposure limits. Furthermore, studies should monitor human intake of total aromatic polycyclic hydrocarbons through various routes of exposure such as: inhalation, skin contact or ingestion [21, 22].

\subsubsection{Air Pollution and the Impact on the Health of the Population in Tirana, Albania}

A study report conducted by Institute of Public Health in 2014 (the first and last of this kind) in Albania assessed the impact of environmental factors on the health of the population through the application of the basic indicators of environmental health, focusing on air quality indicators alone. The report was a positive practice regarding the analysis of basic correlation between public and environment health indicators in Albania, but these reports should be frequent and updated every year. The process of evaluating environmental health indicators is challenging when their users are not experts in the field or active in gathering the original data. The data collected must be valid, scientifically accurate, detailed, consistent, interesting and easy to assimilate by the public [17]. The report used DPSEEA as structured set of indicators, the first set of indicators were the environmental ones, which included data on the driving forces (such as population growth, economic development, technology, production pressure); moreover, data included were consumption and discharge of waste (such as condition, i.e. natural hazards, available resources and levels of air pollutants). Regarding health indicators, the study collected information regarding direct exposure, (the absorbed dose and dose to the target organ; impact on well-being, morbidity and mortality). Other set of indicators analyzed were related to economic and social policies, unused technologies, risk management, environmental improvement through monitoring and control of pollution, education or raising public awareness as well as treatment or rehabilitation [17]. The research further analyzed different transport trends, such as kilometers travelled per type of car and per capita (total number of vehicles, average kilometers per year for vehicle types per total population); fuel consumption per type of transport (total amount of fuel sold in Tirana, and average amount of energy contained in each type of fuel per total population). Furthermore, calculations in the study assessed average consumption of sold gasoline and oil per capita; the air pollutant emissions (data on total emissions like $\mathrm{PM}_{10}, \mathrm{SO}_{2}, \mathrm{NO}_{\mathrm{x}}$ ); concentrations of air pollutants in the urban environment; population overall exposure (data from monitoring of average concentrations of $\mathrm{NO}_{2}, \mathrm{PM}_{10}, \mathrm{SO}_{2}$ and $\mathrm{O}_{3}$ in the air); infant mortality from respiratory diseases; mortality from respiratory diseases for all ages; mortality from cardiovascular disease for all ages; participation in international agreements and environmental initiatives (their ranking) and finally the policies taken by governments to reduce exposure to those pollutants [17]. A number of institutions contributed to the release of the above data, such as: Ministry of Health, Ministry of Transport, General Directorate of Customs, General Directorate of Taxation, Directorate of Civil Status and INSTAT [17]. The report provided a series of recommendations for measuring indicators as detailed as possible in the context. Some of which 
considered the need for improving the vehicle registration system, improving the system of collection and calculation of fuel quantity, increasing laboratory analysis to determine traded fuel items, monitoring and analyzing the lead level in gasoline, extracting continuous data on air pollutant emissions, improving the technology of air monitoring apparatus, improving the reporting system for mortality by diseases, increasing participation in agreements international and environmental initiatives as well as ongoing monitoring of the implementation of air quality policies.

On the other hand, if we refer to the Annual Report on Urban Air Quality, Noise Level and Ecosystem Services from Urban Greenery for the city of Tirana (2020), the concentration of carbon dioxide has been twice above the standard value of the European Union (771 ppm from $350 \mathrm{ppm}$ allowed), in some areas of the city of Tirana, despite the presence of greenery in the same areas [23]. Also, high values have been observed regarding the concentration of nitrogen dioxide in areas with heavy traffic in the capital. In this context, transport and construction are the main source responsible for air pollution in Tirana. Very problematic in the case of Albania are the lack of unified quantitative data on the impact on the environment regarding air, noise, water discharge, waste generation, etc. Also, noise pollution in many areas is significant due to low monitoring and low reports. In addition, 52.8 ha of green area of Tirana is used for housing or other activities [23]. The shrinkage of green spaces leads to an increase in temperatures in residential areas, non-absorption of polluting agents and consequently health problems for residents.

A similar situation was observed in other urban centers of the country. Referring to INSTAT data for 2019, on the death rate in Albania, the values increased compared to the previous year (2018). The main causes of death were "circulatory system" group diseases, such as chronic heart disease, cerebrovascular disease and ischemic heart disease. There is an evident increase in deaths from the group of diseases known as "symptoms and well-defined diseases" as well as "tumors" group-disease, specifically of digestive tract tumors and respiratory tract tumors. Infant mortality rates increased also compared to a year ago due to complications in pregnancy, childbirth and the postpartum period, and diseases appearing in the period around birth [24]. Among the influencing socio-economic factors, the environment was seen as an important factor influencing the above health indicators.

Despite the fact that the Institute of Public Health has a manual of health indicators for Albania [25], the necessary infrastructure is needed to provide sustainable indicators measurements and therefore to build well-informed public health policies in general and the environment in particular. In order to make an accurate assessment of the impact of the environment pollution on public health, experts and professionals in the field are needed, i.e. special university specializations, who provide a professional contribution not only in terms of environmental health statistics at local and national level, but mainly in terms of access to individual-patient focus.

\section{Discussion}

\subsection{Importance and Development of Specific Undergraduate or Postgraduate Programs in the Field of Environmental Medicine in the Case of Albania}

In the Albanian case, in addition to the need of coordinating policies to improve public health in the environmental context as in the above-mentioned case of the EPHT, we see an emerging need for a new field of study which can further connect environmental and population health. The above literature review and analysis showed us that the increasing of urbanization, especially in developing countries, is increasing also the sources of pollution in these countries, endangering the public health directly. Epidemiological and biomonitoring research have raised awareness of the impact of environmental exposures and their association with chronic health diseases. However, while most health professionals acknowledge that environmental toxicants effect on human health, and even though these professionals are often asked by their patients about the risks of exposure to those pollutants, the lack of environmental medicine training and standardized exposure assessment tools, leaves most of these professionals not equipped with adequate skills not only for treatment but also for prevention. Environmental Medicine (EM) practitioners have a key role to play in resolving environmental challenges and preventing diseases of environmental origin to ensure healthy and safe environments for communities [26]. In this regard, they must possess a range of skills integrated into various fields. In addition to clinical medicine, they need to know how toxins affect human health, according to their type. They need to know the possible sources of exposure, based on employment history, place of residence, patient's habits, etc. They should also be able to assess the dose of toxins in their patients' bodies through the interpretation of laboratory tests depending on the problems they present. Furthermore, they should be able to suggest to their patients measures to minimize toxic exposure and other important interventions to improve their health. Awareness is the first tool to prevention. These skills help environmental medicine practitioners to apply this knowledge in a variety of circumstances and have an impact on public health and lifestyle [27]. For example, environmental health practitioners' in sub-Saharan Africa are considered among the main workforce with the necessary skills to support the transdisciplinary approach required to halt the further spread of SARS-CoV-2 [28], a novel severe acute respiratory syndrome which has taken e global hold.

However, adapting their knowledge to the needs of patients is not always clear due to the lack of literature on EM clinical practice and little qualitative research on the perspectives of environmental professionals. EM practitioners can 
be divided into two main groups: integrative physicians (IP) who use knowledge from other medical disciplines to treat patients with chronic, complicated, misdiagnosed conditions involving multiple systems and environment physicians (OEP) who treat employees based on their occupational exposure to toxic substances [29]. However, while in developed countries, these two types of practices exist separately, in Albania neither of them exists. Therefore, there is a need to develop and discuss a curriculum in environmental medicine tailored to Albania and the current situation. In general, based on the literature, didactic and clinical training in occupational and environmental medicine should provide:

- In-depth knowledge in epidemiology and toxicology;

- An accurate understanding of the concept of risk and its application to groups and individuals;

- Method for collecting public and environmental health indicators;

- Dose-response concepts and other factors that contribute to human exposure and their response to them;

- Knowledge and skills in finding and using information related to environmental and occupational diseases;

- Sensitivity to specific medical, ethical, legal and economic factors in the care of patients with environmental or environmental diseases.

Another important aspect of the discussion that deserves attention, is the fact that environmental medicine is an area in which information is often lacking (e.g., regarding exposure, dosage, risk, and health effects) and in which economic risk and political action or inaction due to these factors, is often high. Thus, the ability to make decisions in the face of considerable uncertainty is very important. Physicians should be prepared to advise patients and their communities about environmental health risks, although often little can be known about their long-term health effects. They should also be able to assess how the values (their own and those of others) can influence the questions raised, the problems studied, the recommendations and the actions taken.

Regarding the components of an environmental-medical curriculum that unquestionably relates to much more complex issues of behavioral, social and political aspects, the following conclusion is suggested: any level of involvement of the health professionals in environmental medicine, should be based on a basic level of competence, which, if realistically defined, should be addressed by all undergraduate and postgraduate medical education programs. Helping students to reach this basic level of competence should be the main goal of this curriculum, which in the Albanian context becomes even more difficult to achieve. A realistic curriculum in environmental medicine in Albania should be able to: (1) identify a small set of competencies, (2) easily adapt within existing curricular structures, (3) be reinforced by attending faculty but also residents during clinical rotations, and (4) focus on the area that is unique to the role of the professional in environmental health - namely in preserving human health.

\subsection{Competency-based Learning Objectives-Basic Competencies That a Student in the Field of Environmental Medicine Should Acquire}

The integrated relationship between the environment and health creates the need for active participation of physicians in both environmental and public health issues. As stated earlier in this paper, there are things in the field of environmental health that medical students need to know. Environmental education equips them with a range of competencies needed to properly manage and treat clinical cases. First, medical students should be fully understand the impact that different environmental agents or environment as a whole brings on human health. A healthy outdoor and indoor environment is strongly reflected in public health. The opposite is also true. Physicians need to recognize the link between chemical or physical environmental agents and their acute or chronic health effects. They should be trained in areas such as: epidemiology, toxicology, sources of exposure, etc. Secondly, students should be provided with knowledge on the signs, symptoms, diseases caused by environmental conditions as a whole or exposure to environmental agents. Some environmental agents cause illness, disability, or acute or chronic health problems. The student curriculum should include knowledge of specific agents and environmental conditions, their impact on body organ systems, the diversity of health effects that cause, the possibilities of prevention and patient health monitoring tools. Thirdly, medical students should be able to extract a detailed history of environmental exposure of their patients.

In order for students to identify the etiological agents, the link between them, and diseases or health conditions, they must provide a detailed history of their environmental and occupational exposure in addition to past medical or family history. This helps in clearly defining the risk, diagnosis, therapy, prevention and mitigation measures. The detailed history of environmental and occupational exposure helps students, as prospective physicians to share diseases of various etiologies. Fourth, students must be able to identify and use strongly both clinical and environmental information. They should use different sources of information such as medical databases, public health specialist's consultancy, Environmental and Occupational Medicine books and research tools, government agencies, employees of various public and private entities, etc. This will help students, as future doctors, to orient the patient in the right way, to know where to look for information, etc. Fifth, students should have skills in using research 
methodologies, i.e. not only to identify adequate data sources, but also to archive large or small datasets into the database and analyze environmental and health indicators for further and general use. The data can better help government and indicate the needed policies for public health safeguard. Equipping the Environmental Medicine students with research skills, and qualitative and quantitative data processing enables them to benefit from the latest scientific findings regarding the impact of environmental indicators on public health indicators, but also improving patient treatment and management. Furthermore, Environmental Medicine students should be able to make their scientific contribution based on the cases identified in medical practice by helping to share and process data into relevant databases. Increasing the number and quality of publications in the field of environmental health serves not only the local context, but also nationally and internationally. Sixth, medical students need to be able to simplify the information they give their patients to apply risk reduction strategies. In order for physicists to meet the expectations of public opinion, as the most reliable source of information about the risks of exposure to harmful environmental agents, they must have extensive knowledge in the field; have communication and advisory skills to adapt to the concerns of their patients in this regard. Seventh, students need to understand their legal and ethical responsibilities in caring for patients who exhibit environmental health concerns or problems. Environmental and Occupational Medicine professionals must meet the legal obligations of reporting environmental and occupational diseases by helping patients receive compensation and adequate rehabilitation process. They also have an ethical obligation to report to local authorities and the community the harmful effects of environmental agents on health.

Environment is a very important factor in public health. For this reason, every medical school graduate should have knowledge and have acquired competencies in the basic elements of environmental medicine. These competencies can only be enhanced through extensive knowledge and skills in both environmental and public health education.

\section{Conclusions}

Environment and public health are strongly linked. The emerging need for Environmental Medicine development in Albania is evident. This emerging need is based on the increasing evidence of a set of indicators related to environmental pollution, as well as public health problems (such as infant and general mortality, increasing morbidity rates, including respiratory diseases), that originates mainly from environment harmful agents. Currently, there is a lack of a professional medical practice specifically focused on environmental toxicity. Adequate infrastructure and instruments needs to be build. Furthermore, public health policies should be based on more accurate data deriving from those professionals nationally and internationally. In Albania, the most important institutions for measuring and reporting environmental and health indicators are the Institute of Public Health, the National Environmental Agency and INSTAT. In the fragile actual health system infrastructures in Albania, the operation and potential capacities for measuring and correlating environmental and health indicators are limited. The Institute of Public Health has published some reports regarding demographic and health surveys in Albania, a Handbook of Health Indicators for Albania, etc., but there is still no specific system nor methodology, similar to the Environmental Public Health Tracking for instance, which includes all in one indicators related to the correlation of environmental and public health. In terms of education, the concept of "environmental health" is part of modules in some nursing study branches, but it has not yet become a complete curriculum or study program. Vocational training in health and environment is distributed in public some health disciplines and some courses in different faculties related to environmental studies, however a full integrated university program is missing.

The two case studies analyzed in this study showed some practices that can be followed by environmental medical professionals in order to assess the environmental and individual health of patients. In addition, based on research findings, Environmental Public Health Tracking is an instrument that can be applied also in the Albanian context. Applying this instrument can enable the analysis of complex data sets, by addressing different audiences and supporting environmental health messages tailored to each audience, such as the public, professionals, stakeholders, and decision makers. Moreover, it helps to evaluate public health at the global level. In this context, future environmental medicine professionals should develop and provide data which can support the creation of a complete database. Furthermore, those indicators can contribute to create a Geographic Information System in the field of Public Health and Environment, to make a clear assessment of both sets of indicators, correlating them with one another, and furthermore propose research based policies to increase the general public health indicators in Albania. There is a need to increase and concentrate the capacities of public health professionals, researchers, etc., not only in Albania, but also globally.

In conclusion, environmental and public health professionals need to communicate continuously with the public regarding all relevant information and data on the correlation between environment and public health. Research and university curricula (specifically the Environmental Medicine discipline) should be made a government priority not only to manage the environmental and public health correlation consequences, but also to build appropriate policies and action plans to prevent the occurrence of environmental diseases. 


\section{Declarations}

\subsection{Author Contributions}

F.K. contributed to conception, design of the study as well as wrote the whole manuscript. Author has read and agreed to the published version of the manuscript.

\subsection{Funding}

The author received no financial support for the research, authorship, and/or publication of this article.

\subsection{Acknowledgements}

This paper and the research behind it would not have been possible without the exceptional support of and my supervisor at Polis University, Prof. Dr. Sherif Lushaj. Also, I would like to acknowledge my colleague M.Sc. Teodora Kita and Ph.D. Ville Korpela who both looked over my transcript.

\subsection{Ethical Approval}

This research article has not any ethical implications and does not address any issues arising.

\subsection{Data Availability Statement}

No new data were created or analyzed in this study. Data sharing is not applicable to this article.

\subsection{Conflict of Interest}

The authors declare that they have no known competing financial interests or personal relationships that could have appeared to influence the work reported in this paper.

\section{References}

[1] World Health Organization (2021). Report. Air Pollution. Available online: https://www.who.int/health-topics/airpollution\#tab=tab_1 (accessed on 06 January 2021).

[2] BBC News (2020). EU says one in eight deaths is linked to pollution. Available online: https://www.bbc.com/news/worldeurope-54071380 (accessed on 06 January 2021).

[3] NPR (2017). NPR Report: Pollution Kills 3 Times More than AIDS, TB and Malaria Combined. Available online: https://www.npr.org/sections/goatsandsoda/2017/10/19/558821792/report-pollution-kills-3-times-more-than-aids-tb-andmalaria-combined (accessed on 06 January 2021).

[4] European Envrionment Agency (2019). Healthy environment, healthy lives: how the environment influences health and wellbeing in Europe. EEA Report, 21, 7. Available online: https://www.eea.europa.eu/publications/healthy-environment-healthylives (accessed on 02 January 2021).

[5] Ganzleben, C., \& Kazmierczak, A. (2020). Leaving no one behind - understanding environmental inequality in Europe. Environmental Health, 19(1). doi:10.1186/s12940-020-00600-2

[6] Vassilev, Z. P., Robson, M. G., \& Kaplan, M. B. (1999). Health - based environmental indicators: approaches, potential and limitations. Journal of Environmental Medicine, 1(4), 201 - 206. doi:10.1002/jem.31.

[7] World Health Organization (2010). Progress on Sanitation and Drinking Water - 2010 Update. Available online: https://www.who.int/water_sanitation_health/publications/9789241563956/en/ (accessed on 16 January 2021).

[8] Ladou J., \& Harrison R. (3rd Ed.). (2014). Current diagnosis and treatment. Occupational and Environmental medicine McGraw-Hill Professional.

[9] Snashall, D. \& Patel, D. (3rd Ed.). (2012). ABC of Occupational and Environmental Medicine. United Kingdom: John Wiley \& Sons, Ltd. Available online: https://download.e-bookshelf.de/download/0000/7527/11/L-G-0000752711-0002367477.pdf (accessed on 16 January 2021).

[10] Luch, A. (Ed.). (2012). Molecular, Clinical and Environmental Toxicology. Experientia Supplementum. doi:10.1007/978-37643-8340-4

[11] Manisalidis I., Stavropoulou E., Stavropoulos A., \& Bezirtzoglou E. (2020). Environmental and Health Impacts of Air Pollution: A Review. Frontiers in Public Health, 8:14. doi:10.3389/fpubh.2020.00014.

[12] Lauriola, P., Crabbe, H., Behbod, B., Yip, F., Medina, S., Semenza, J. C., ... Leonardi, G. S. (2020). Advancing Global Health through Environmental and Public Health Tracking. International Journal of Environmental Research and Public Health, 17(6), 1976. doi:10.3390/ijerph17061976. 
[13] Wiscosin Department of Health Sciences (2020). Environmental Public Health Tracking: Air Quality Data. Available online: https://www.dhs.wisconsin.gov/epht/air.htm (accessed on 16 January 2021).

[14]University of Tirana (2011). Environmental Health. Accessed online at: https://sites.google.com/a/infermieria.info/home/degete-studimit/mami/viti-i/shendet-mjedisor (accessed on 16 January 2021).

[15] National Environmental Agency (2019). State of the Environment Report 2019. Available online: http://www.akm.gov.al/assets/rgjm-2019.pdf (accessed on 16 January 2021).

[16] Institute of Public Health (2020). ISHP. Available online: http://www.ishp.gov.al/ (accessed on 16 January 2021).

[17] Institute of Public Health (2014). Report on basic health-environment indicators (air quality). Available online: http://ishp.gov.al/wp-content/uploads/2015/04/Health-report-English-version.pdf (accessed on 16 January 2021).

[18] State Inspectorate of Labor and Social Services (2020). Occupational medicine services. Available online: https://inspektoriatipunes. gov .al/ sq/ sherbimet-e MDesise-se-punes/ (accessed on 16 January 2021).

[19] INSTAT (2018). Public Health Indicators. Available online: http://www.instat.gov.al/al/temat/kushtetsociale/sh\%C3\%ABnde t\%C3\%ABsia/publiimet/2019/Markers-e sh\% C3\% ABndetit-public-2018/ (accessed on 16 January 2021).

[20] Schwartz, B. S., Rischitelli, G., \& Hu, H. (2005). Editorial: The Future of Environmental Medicine in Environmental Health Perspectives: Where Should We Be Headed? Environmental Health Perspectives, 113(9). doi:10.1289/ehp.113-1280414.

[21] Çipa, M. (2018). Study of the extent and effects of long-term exposure of workers at the Ballsh deep oil refinery to chemical pollution. Dissertation, University of Tirana. Available online: https://drive.google.com/file/d/1DQeyf9vVy3TW0Wvhtl MtquVUsgqL9Ui/view (accessed on 16 January 2021).

[22] Neris, J. B., Olivares, D. M. M., Velasco, F. G., Luzardo, F. H. M., Correia, L. O., \& González, L. N. (2019). HHRISK: A code for assessment of human health risk due to environmental chemical pollution. Ecotoxicology and Environmental Safety, 170, 538-547. doi:10.1016/j.ecoenv.2018.12.017.

[23] CoPlan (2020). Green lungs for our cities. Annual report on urban air quality, noise level and ecosystem services from urban greenery. Available online: http://www.co-plan.org/en/mushkeri-te-gjelbra-per-qytetet-tona/ (accessed on 16 January 2021).

[24]INSTAT (2019). Causes of death. Available online: http://www.instat.gov.al/media/7135/causes-of-deaths-2019.pdf (accessed on 16 January 2021).

[25] Institute of Public Health (2015). Common European Health Indicators; Manual of Health Indicators for Albania. Available online: http://ishp.gov.al/wp-content/uploads/2015/04/libri-indikatoreve-final.pdf (accessed on 16 January 2021).

[26] Shezi, B., Mathee, A., Siziba, W., Street, R. A., Naicker, N., Kunene, Z., \& Wright, C. Y. (2019). Environmental health practitioners potentially play a key role in helping communities adapt to climate change. BMC Public Health, 19(1). doi:10.1186/s12889-018-6378-5.

[27] Patthanaissaranukool, W., Fongsatitkul, P. \& Warodomrungsimun, Ch. (2020). Environmental Health Professionals in Developed Countries. EnvrironmentAsia 13(1), 112-123. doi:10.14456/ea.2020.11.

[28] Morse, T., Chidziwisano, K., Musoke, D., Beattie, T. K., \& Mudaly, S. (2020). Environmental health practitioners: a key cadre in the control of COVID-19 in sub-Saharan Africa. BMJ Global Health, 5(7), e003314. doi:10.1136/bmjgh-2020-003314.

[29] Bijlsma, N., \& Cohen, M. M. (2018). Expert clinician's perspectives on environmental medicine and toxicant assessment in clinical practice. Environmental Health and Preventive Medicine, 23(1). doi:10.1186/s12199-018-0709-0. 